\title{
A CONSTRUÇÃO INTELECTUAL DOS MERCADOS AGRÍCOLAS: A SOCIEDADE FRANCESA DOS ECONOMISTAS RURAIS E A REVISTA ECONOMIE RURALE
}

\author{
Marie-France Garcia Parpet
}

A economia é uma fotografia da realidade ou um elemento de formatação da realidade social? Publicações mais ou menos recentes em ciências sociais testemunham o interesse por esta problemática - em posições e domínios de observação diversos (Cf. Garcia-Parpet 1996; Mackenzie et alli 2007; Neiburg 2006). ${ }^{1}$ Neste artigo, nós propomos a nos debruçar sobre as transformações ocorridas na agricultura francesa no período do pós-guerra. Para tanto, estudamos a criação e a produção da revista Economie Rurale, analisando seus enunciados, a identidade social de seus autores, procurando associá-los ao espaço social e científico no qual se inscrevem, o que deveria permitir a compreensão de sua conexão prática com a ciência e a realidade econômicas. Mais precisamente, desejamos ver, através do filtro constituído pela revista, o papel das instituições de pesquisa e dos cientistas que contribuíram para a mudança radical vivenciada pela França rural nos trinta anos que se seguiram à Liberação, verdadeira revolução técnica, econômica e simbólica, após a qual o "camponês" tornou-se "agricultor", "dirigente de empresa".2

Ao analisar os artigos da revista e as produções conexas, procuramos compreender em que medida a revista contribuiu para forjar e transmitir esquemas de percepção da atividade econômica e das práticas que permitiriam ao movimento da Juventude agrícola católica e à sua representação no sindicalismo (CNJA) - que apostavam no progresso técnico e na organização dos produtores para assegurar a promoção social e humana da massa dos pequenos produtores (Duby \& Wallon 1976) ${ }^{3}$ - impor um modelo de exploração agrícola limitado ao período de criação e aos 25 primeiros anos de seu funcionamento, ou seja, os anos que se seguiram às leis de orientação agrícola. ${ }^{4}$ 


\section{Entre poder, ciência e profissão}

A revista, atualmente conhecida como Economie Rurale, surgiu pela primeira vez em 1949. Era a expressão dos debates que ocorriam no seio da Société Française d'Economie Rurale, criada em 1948, uma associação (alocada sob o regime da lei de 1 de julho de 1901, ou seja, sem fins lucrativos) que se propunha a "promover estudos de economia rural de caráter científico versando sobre problemas econômicos e sociológicos da França e da União francesa; comparar as situações econômicas e sociais da França com a de países estrangeiros; precisar, mediante a reunião de estudos e discussões, as observações recolhidas por seus membros e difundi-las por meio de conferências e publicações" (Bulletin de la Société Française d'Economie Rurale 1949:26). Esta associação ${ }^{5}$ reunia-se periodicamente para a apresentação de trabalhos que eram submetidos à discussão por seus membros. O resumo dessas reuniões, acrescido de uma bibliografia comentada, era publicado em seguida em um periódico intitulado Bulletin de la Société d'Economie Rurale - que, em 1953, passaria a se chamar Economie Rurale.

Esta fórmula vigoraria por muitas décadas, seguida de um distanciamento em relação à Société Française d'Economie Rurale, momento em que se instituiu um comitê de redação independente desta última, o que permitiu a ampliação das publicações, incluindo autores não vinculados à associação e a adequação das exigências de produção em direção ao polo científico. Para caracterizar o espaço social no qual esta associação e a publicação que dela emanava surgiram, é interessante perceber que o conteúdo do primeiro número ao qual havíamos feito referência para caracterizar o objetivo da associação, apareceu igualmente sob o título Etudes et Monographies, République française, Ministère de l'Agriculture, indício da proximidade do espaço próprio ao poder político em meio ao qual os economistas iriam conceber seu projeto.

A iniciativa da criação da SFER e da revista Economie Rurale se deve a Denis Bergman, um professor assistente de Economia Rural no antigo Institut National d'Agronomie (a mais importante escola superior de agronomia na França), judeu cujas circunstâncias de guerra o levaram a estudar em uma universidade americana. Foi, por um lado, o modelo do American Journal of Farm Economics e, segundo a introdução do repertório bibliográfico de Nicole Tanguy, "a ideia cultivada por ocasião de uma estadia em Oxford de criar um 'clube', um lugar que permitiria reunir em um contexto informal os economistas, pouquíssimo numerosos na ocasião e, ainda assim, bastante divididos, para instigar laços, trocas entre os autores" que iriam inspirar D. Bergman (Tanguy 1991: introdução). Segundo esta mesma fonte - 
confirmada pelo discurso do presidente da nova associação - este último, acompanhado por M. J. Chombart de Lauwe, professor de economia rural na Ecole de Grignon e conselheiro estatístico na Organização das Nações Unidas para a Agricultura e a Alimentação, solicitaram a colaboração de M. Augé-Laribé - simultaneamente conhecido nos meios profissional, ministerial e universitário - para dar credibilidade a seu projeto.

Augé-Laribé, que estudou direito e defendeu em 1902 uma tese sobre a história das doutrinas sobre a repartição dos solos e a transformação industrial da agricultura na França, em Montpellier, teve um importante papel nas organizações profissionais agrícolas, seu nome permanecendo vinculado à atividade da Confédération Nationale des Associations Agricoles e da Association pour l'Exportation des Produits Agricoles. Em 1929, ele contribuiu para a redação do programa do Partido Radical Socialista (Debroux 2004). A partir de 1935, representou a França no Instituto Internacional de Agricultura, em Roma, no qual teve uma influência preponderante na orientação dos trabalhos deste organismo em direção ao estudo dos problemas econômicos. Durante a Segunda Guerra Mundial, Augé-Laribé criou o Serviço de Documentação do Ministério da Agricultura. Autor de diversas obras publicadas antes da criação da SFER (Augé-Laribé 1907, 1923, 1926, 1941) e professor de economia rural no Instituto Nacional de Agronomia, ele foi um universitário suficientemente reconhecido para apoiar a solicitação de financiamento junto ao CNRS para a rede "Economia e Humanismo" do padre Lebret (Pelletier 1996), cujos egressos se fariam bastante presentes na associação e em suas publicações durante os primeiros anos que se seguiram à sua criação.

Tal como os jovens "economistas"6 que lhe haviam solicitado a criação da associação, Augé-Laribé também desejava uma agricultura "industrializada e comercializada", uma visão da agricultura que se distanciava claramente daquela dos principais responsáveis políticos e profissionais da época. Ele exaltava a concorrência entre os produtores e lutou com afinco pela livre troca, enquanto os últimos satisfaziam-se tão somente com a performance da agricultura francesa, em franco crescimento. Ao estabelecer uma comparação com a produção da Alemanha e da Inglaterra, este autor lamentava o fato de que "entre nós, os resultados de conjunto eram menos brilhantes porque uma massa de pequenos produtores ignorantes e pobres arrasta-se, lentamente, a reboque daqueles que lhes mostram o caminho" (Augé-Laribé 1912:56).

Preocupado com a definição de economia rural, ele dedicou quatro artigos e várias discussões aos termos a serem utilizados, distinguindo particularmente a economia rural "conjunto de observações metódicas, leis e 
preceitos da economia política quando são aplicados ao trabalho e à vida dos agricultores, às suas relações com as outras profissões, ao lugar da agricultura nas sociedades nacionais e nas trocas internacionais" da economia agrícola: "ramo da economia rural que estuda a empresa agrícola, as relações entre seus diversos elementos, as condições da produção e da troca com vistas à produção de lucro" (Augé-Laribé 1949a:31). Dito de outro modo, a exploração familiar agrícola é pensada, antes de mais nada, como uma empresa industrial, e o trabalho aí realizado, como um trabalho assalariado.

Segundo M. Cépède e M. J. Chombart de Lauwe (1969), "dizia respeito tanto à profissão quanto à função pública", e foi exatamente neste espaço, que ultrapassava amplamente a academia, que estes "economistas" inovadores tentaram impor suas ideias. Testemunha disto é a composição da primeira direção da associação e a afiliação institucional dos membros da associação e dos autores.

Por ocasião de sua criação, em 1948, dos 12 membros que compunham a coordenação da SFER, oito eram professores, a maioria acumulando cargos importantes no Ministério da Agricultura. Entre os outros membros, figuravam como vice-presidente o diretor do maior banco de crédito rural (Caisse Nationale de Crédit Agricole); como tesoureiro, o diretor da divisão de compatibilidade da Confederação Geral da Agricultura (CGA); um membro da Associação Geral dos Produtores de Trigo e um agrônomo. Em 1950, um encarregado da missão do comissariado figurava entre os membros da direção da entidade. A revista, cujo secretariado foi inicialmente assegurado gratuitamente pela Divisão de Rentabilidade da CGA - sendo o próprio Augé-Laribé quem revisava os textos - beneficiava-se de um pequeno financiamento do Ministério da Agricultura e de doações provenientes de fontes diversas. Assim, em 1953, figuravam entre os membros benfeitores da Revista: a Associação Geral de Produtores de Linho, a Caisse Nationale du Crédit Agricole, o Sindicato Profissional da Indústria dos Fertilizantes à Base de Nitrogênio, a Sociedade Shell francesa, a União Nacional das Cooperativas, o Centro Agronômico da Companhia de Saint-Gobin e a Divisão de Rentabilidade da CGA. ${ }^{7}$

Em 1956, a sociedade que contava inicialmente com cerca de 60 membros $^{8}$ já tinha mais de 400, e seu relatório, realizado por M. J. Chombart de Lauwe, chamava a atenção para a necessidade de se recrutarem novos membros nos meios agrícolas e não-agrícolas, sobretudo pesquisadores da ciência econômica e funcionários técnicos do Ministério da Agricultura, Serviços de engenharia rural, Serviços agrícolas etc.). As sessões da SFER eram frequentadas e dirigidas por professores, administradores, representantes das organizações profissionais, refletindo uma diversidade na relação 
com o mundo agrícola que remetia às profissões dos interessados e às suas posições políticas. Foi assim, por exemplo, que em oposição às visões modernistas dos iniciadores da sociedade, nela figurava, entre outros, Roland Maspetiol, advogado extremamente conservador, autor de L'ordre éternel des champs, essai sur l'histoire, l'économie et les valeurs de la paysannerie (Maspetiol 1946), membro ativo da revista que para ela produziu diversas resenhas de livros e de autores.

A produção da revista refletia a própria diversidade dos autores, como podemos observar no repertório bibliográfico elaborado por N. Tanguy (1991). Ali figuravam tanto agricultores quanto representantes das organizações agrícolas e políticos (Debatisse 1974; Chalmin, Pisani \& Debatisse 1988), agentes de vulgarização, representantes dos bancos, organizações econômicas (cooperativas, indústrias alimentares, membros da administração [agrícola ou não], altos funcionários do governo (Mansholt 1973), membros do ensino superior ou mesmo secundário, pesquisadores de organismos de pesquisa públicos, privados ou de sociedades científicas). Como podemos observar no quadro reproduzido na página 81, professores e pesquisadores eram minoritários até a década de 1970 e representavam dois terços da produção da revista no período 84-88. Por sua vez, a proporção na revista de agricultores e de representantes de organizações profissionais passou de $12,33 \%$ no período $1949-1953$ a 6,4\% no período 1984-1988. A proporção dos autores ligados a administrações evoluiu de $21,11 \%$ no período $1949-1953$ para $12,88 \%$ no período $1984-1988$.

Uma análise mais aprofundada permitiria dar conta do leque de publicações dos economistas rurais até a década de 1960 e melhor qualificá-los no campo da ciência econômica então em vias de constituição. A disciplina econômica somente atingiria plena independência por volta do final dos anos 1960, o estudo das ciências econômicas sendo realizado em disciplinas opcionais no interior dos cursos de direito. A análise de Michael Pollak (1976) sobre a institucionalização das ciências sociais, nessa mesma época, revela um número muito restrito de revistas em que os economistas podiam se expressar (segundo este autor, existia somente a Revue d'Economie Politique, e a explosão do número de publicações produziu-se somente a partir dos anos 1960 para a economia e a sociologia) e situa a Economie Rurale relativamente mais próxima do polo intelectual do que do polo do poder. Uma confrontação com as revistas Economie Politique e L'Economiste Français, de P. Leroy-Baulieu, professor de economia política no Collège de France, permitiria melhor situar o espaço das publicações e, consequentemente, o perfil dos economistas que investiram na criação da SFER e na publicação da Economie Rurale. 
Raros são os artigos provenientes de economistas cuja produção não versasse sobre a economia rural, fato por várias vezes lamentado pelos dirigentes da revista. As exceções que pudemos localizar, por ocasião da publicação de dois números especiais, são representativas da ligação que estes últimos mantinham com os primeiros na hierarquia dos temas próprios ao campo científico e suas relações com os diferentes agentes dos quais emanava uma demanda social. O número especial dedicado aos contratos (Economie Rurale 1964a) tem início com o artigo "La place de l'économie contractuelle dans l'économie française", de André Piettre, professor na Faculdade de Direito e de Ciências Econômicas na Universidade de Paris, instituição na qual, por excelência, se ensinava economia (Piettre 1964).

Em seguida, há artigos sobre agricultura contratual nos Estados Unidos de J-C. Dubourgnoux, da Société de Financement et de Développement de l'Agriculture (SOFIDECA), sobre o efeito da rede na comercialização dos produtos agrícolas perecíveis; de M. Le Gouis, auxiliar de direção da Société Centrale pour l'Equipement du Territoire, sobre a constituição dos grupos de produtores e de comitês econômicos agrícolas, a análise crítica da lei sobre a economia contratual, a posição dos industriais diante da economia contratual, a posição dos agricultores diante da economia contratual, o estado dos grupos de produtores, os aspectos da economia contratual na perspectiva de expansão; e as conclusões da sessão da SFER de maio de 1964, de Ph. Mainié, pesquisador no INRA (Belhomme; Dubourgnoux; Le Gouis; Moreaux; Génin; Douroux; Fabrègues; Dupuis; Mainié 1964).

Pode se constatar uma distribuição análoga na apresentação de um número especial dedicado às cooperativas (Economie Rurale 1964b). Após um artigo de Yves Tavernier, da Fundação Nacional das Ciências Políticas, sobre a crise camponesa, há os trabalhos sobre as cooperativas: Henri Denis, professor da Faculdade de Direito e Ciências Econômicas de Paris, apresentando um estado da arte que permitia inscrever os projetos relacionados à agricultura e as evoluções do mundo agrícola nas profundas transformações vivenciadas pela França e por toda a Europa naquela época. Em seguida, há os textos dedicados à doutrina cooperativa e à cooperação agrícola, uma tentativa de repensar a filosofia e os objetivos da cooperação, de L. Malassis; um artigo sobre uma região específica, a cooperação agrícola na Bretanha; outro sobre o poder de decisão na cooperativa ou ainda sobre a formação dos agricultores, dos administradores e dos quadros na cooperação agrícola; por fim, um artigo sobre os problemas colocados pela expansão do movimento cooperativo (Denis; Tavernier; Lopes-Cardoso; Malassis; Le Bihan; Moisan; Selariés 1964). 
Vemos aqui reunida uma produção que reflete os esquemas de pensamento e as instituições dominantes no campo científico e na política nacional, as perspectivas institucionais de construção ou remanejamento consideradas, e os problemas ligados à adequação das disposições econômicas dos agentes envolvidos. Se pudermos apreender de que modo o mercado, suas instituições e as práticas dos agentes são o resultado de uma construção simbólica e política, também poderemos observar a abertura deste espaço que acolhia tanto os defensores da economia dominante, com A. Pietre, como os defensores da escola marxista, com H. Denis.

\section{Evolução das afiliações dos autores de 1949 a 1988 (quadro resumo)}

\begin{tabular}{|c|c|c|c|c|c|c|c|c|}
\hline$\%$ & $\frac{1949}{1953}$ & $\frac{1954}{1958}$ & $\frac{1959}{1963}$ & $\frac{1964}{1968}$ & $\frac{1969}{1973}$ & $\frac{1974}{1978}$ & $\frac{1979}{1983}$ & $\frac{1984}{1988}$ \\
\hline Agricultores, O.P.A. & 12,22 & 12,88 & 14,52 & 11,11 & 13,28 & 11,16 & 4,52 & 6,44 \\
\hline Setor bancário & 4,44 & 3,03 & 2,42 & 5,78 & 1,17 & 1,59 & 0,59 & 1,07 \\
\hline $\begin{array}{l}\text { Organizações } \\
\text { econômicas }\end{array}$ & 3,33 & 4,55 & 0,81 & 10,67 & 8,59 & 7,37 & 4,72 & 6,22 \\
\hline Administrações & 21,11 & 24,24 & 14,52 & 6,22 & 7,42 & 8,17 & 7,86 & 12,88 \\
\hline Ensino & 38,89 & 32,58 & 34,68 & 24 & 21,46 & 29,68 & 31,24 & 32,83 \\
\hline Pesquisa & 5,56 & 15,91 & 30,65 & 36,89 & 36,33 & 36,85 & 43,42 & 34,33 \\
\hline $\begin{array}{l}\text { Organizações } \\
\text { das estatísticas }\end{array}$ & 3,33 & 3,79 & 2,42 & 1,78 & 5,08 & 2,99 & 3,93 & 2,36 \\
\hline $\begin{array}{l}\text { Organizações europeias } \\
\text { e internacionais }\end{array}$ & 1,11 & 1,52 & & 3,11 & 5,08 & 2,19 & 2,95 & 3,43 \\
\hline Revistas & 10 & 1,52 & & 0,44 & 1,56 & & 0,79 & 0,43 \\
\hline Total de afiliações & 100 & 100 & 100 & 100 & 100 & 100 & 100 & 100 \\
\hline
\end{tabular}

Fonte: Tanguy, Nicole. 1991. Répertoire bibliographique rétrospectif de la Revue Economie Rurale, 1949-1988, Décembre 91, INRA, pp.344-345. 


\section{Economia e economia rural: definição das práticas e das instituições pertinentes}

Ao invés de buscar a validação de seus discursos unicamente no reconhecimento de seus pares e de dirigir suas atenções para produções abstratas, os economistas rurais encaminharam seus esforços no sentido de guiar uma ação que vai da organização dos quadros institucionais, os mais centrais em termos nacionais, passando por todos os quadros institucionais intermediários, até a instauração das contas de gestão, ou seja, a adoção de uma nova maneira de perceber a atividade agrícola. Augé-Laribé e Chombart de Lauwe definem a tarefa a que se propõe esta última:

Fornecer materiais de qualidade controlada àqueles que têm por tarefa a construção de uma política econômica, social construtiva da agricultura em uma sociedade em evolução. Em resumo, nossa sociedade propõe-se a fazer avançar a ciência, mas atribui prioridade aos estudos cujas conclusões sejam suscetíveis de aplicação prática.

[Sua produção é destinada à] totalidade dos professores de economia rural, a certo número de organizações profissionais agrícolas, a alguns funcionários das administrações centrais, mas seria imprudente não constatar que ainda não conseguimos atrair um número suficientemente grande de economistas (generalistas ou especialistas) e sobretudo técnicos (agricultores, engenheiros de serviços agrícolas e da engenharia rural, membros da pesquisa agronômica). Ora, será justamente estabelecendo uma colaboração estreita entre técnicos e economistas que acentuaremos o caráter original de nossa sociedade e que responderemos aos interessados que, se nem sempre se manifestaram, nem por isso deixam de existir. Trata-se, em resumo, de conferir à economia rural o lugar de primeira escolha que ela deve ocupar no conjunto das ciências agronômicas ${ }^{9}$ (Augé-Laribé \& Chombart de Lauwe 1953).

Esta declaração evidencia o fato de que os agrônomos não podiam se beneficiar do êxito no resultado de suas pesquisas em função de os agricultores, ou melhor, os camponeses, não tendo as disposições necessárias para pensarem sua gestão segundo um modelo mais amplo de concorrência, não perceberem suas inovações como um trunfo essencial na rentabilidade de sua atividade. As ideias professadas por Louis Malassis - assistente na Ecole Nationale d'Agriculture de Rennes, em seguida professor titular nesta mesma instituição, tendo investido desde o primeiro momento na SFER e sendo um dos autores que mais contribuíram com a revista (21 artigos na 
E. R. $)^{10}$ - são reveladores da natureza dos trabalhos realizados no seio da associação. Concluindo uma série de conferências dedicadas à questão dos investimentos e que constituem um número especial da Revista, ele se expressa do seguinte modo:

Podem se extrair regras com vistas a guiar a ação? Esta questão poderia ser colocada ao final de cada uma das sessões organizadas pela SFER, já que esta sociedade se dirige a técnicos e a responsáveis em níveis diversos pela gestão econômica. Desta perspectiva, a realização de qualquer teoria econômica significa, de fato, a formulação de regras para a ação.

Ele deduz daí que é preciso aperfeiçoar e vulgarizar a técnica do orçamento por métodos de formação e de informação apropriados, de tal modo que a decisão em investir sempre esteja fundada em um cálculo econômico anterior.

É preciso desenvolver a pesquisa agronômica e econômica com vistas a reduzir a importância relativa dos elementos não mensuráveis no conjunto dos elementos que concorrem para a decisão e incrementar, deste modo, a racionalidade e a eficácia da ação $[. . .]^{11}$ criar ou reforçar as instituições de desenvolvimento econômico e, sobretudo, coordenar as políticas de setor e de zonas por meio de uma melhor integração dos projetos particulares no seio do plano nacional de desenvolvimento econômico e social (Malassis 1957:43, 45).

Nos primeiros anos que se seguiram à criação da Revista, as preocupações dos autores inscreviam-se diretamente na linha do plano Monnet e do plano Marshall (plano de reconstrução econômica nacional após a Segunda Guerra Mundial), nos quais a mecanização era reconhecida como um investimento de base, e a produtividade, um guia de ação da mesma ordem que a justiça social (Duby \& Wallon 1976). Testemunha disto é um número especial que teve, segundo Bergman, um enorme sucesso, dedicado à "Utilização dos tratores agrícolas em algumas regiões da França" (Bulletin de la SFER 1951), do qual participaram, particularmente, Michel Cépède, professor da Ecole de Grignon (uma das mais importantes escolas de agronomia da França) e membro do Serviço de Pesquisa e Documentação do Ministério da Agricultura, pesquisadores do Instituto Nacional de Análise Estatística e de Estudos Econômicos e membros do Serviço Agrícola Shell Francesa e da Direção Nacional das Fábricas Renault. O fato de que não figure nenhum nome de autor ou de coordenador, mas tão somente os agradecimentos das pessoas que ajudaram na preparação e na execução da pesquisa é revelador 
do caráter particular desta produção, na qual cientistas e agentes econômicos diretamente interessados na plena realização do plano juntavam seus esforços. Os artigos sobre a produtividade são particularmente numerosos nessa época (Bustaret 1951; Voisin 1953; Remery 1953; Moreau 1955).

Um bom número daqueles que se definem como economistas rurais realizaram, na realidade, análises de gestão. ${ }^{12}$ A partir deste fato, pode se compreender sua posição no campo científico, acumulando a escolha de estudos mais próximos a escolhas concretas — privilegiando a gestão em oposição a temas abstratos como o equilíbrio geral - e um domínio de reflexão que ocupa um lugar menos elevado na hierarquia social que a indústria ou a finança. Tal como os sociólogos do pós-guerra que se inspiraram ou importaram métodos e técnicas da sociologia empírica americana, ${ }^{13}$ os "economistas rurais" tomaram como referência o modelo de agricultura americano para pensar o futuro da agricultura francesa, incluindo sua relação com a gestão e a comercialização. Não somente os artigos dedicados aos Estados Unidos são mais numerosos do que aqueles sobre os demais países, ${ }^{14}$ como servem ainda hoje de referência. Como ressalta Bergman, a produção de ponta em matéria de programação linear vem dos EUA ou da URSS (com Leontief), e o trabalho dos economistas rurais na França consistiu na pesquisa de um processo mais específico na implantação do conselho de gestão das explorações agrícolas, o que constituiu a primeira tarefa dos economistas do INRA - prioridade bastante oportuna, segundo ele. De fato, para desenvolver o conselho de gestão, era preciso normalizar suas regras (Bergman 1973:118). Em suma, os economistas rurais na França mais do que inovarem nesta matéria desenvolveram seus métodos. ${ }^{15}$

Houve o desenvolvimento do primeiro centro de gestão, em 1954, no departamento do Eure, sob inspiração de Chombart de Lauwe, com a ajuda de Mendès-France, ${ }^{16}$ e o recrutamento de alguns pesquisadores em economia no INRA, em 1956 - saudados por D. Bergman em um artigo de balanço da pesquisa em economia rural (Bergman 1964b) como renovação da disciplina desde a Liberação. A obra de Chombart de Lauwe sobre a Gestion des exploitations agricoles (1957) foi igualmente mencionada por Philippe Mainié, pesquisador no INRA, em uma resenha publicada na revista Economie Rurale, esta sendo "uma publicação com a qual os economistas rurais ficarão muito felizes". Esta última, "sem ser primária, permanece próxima à realidade e constitui um documento de trabalho imediatamente utilizável para o homem de ação que é o conselheiro de gestão", ilustra bem as intenções dos economistas. É apresentado como um "manual elementar de gestão", apoiando-se sobre o exemplo do centro de gestão do Eure... Os autores: 
afastam-se de "aperfeiçoamentos pretensamente científicos", inspirados pelo "pedantismo" e que levam a "perder o contato" com o agricultor. Eles terminam por propor um esquema extremamente flexível de gestão na França, bem como preciosos conselhos aos especialistas em gestão. Nenhuma obra tratando da gestão existia até hoje (Mainié 1957:42).

Numerosas são as publicações dedicadas à racionalização da exploração (Moreau 1959; Poitevin 1959; Sauvage 1964), aos métodos de cálculo de custo de produção agrícola (Tugault 1949; Ratineau 1949), às referências necessárias em economia rural — que ocorreram por ocasião da publicação de um número especial, bem como de outro sobre os investimentos (Economie Rurale 1957) aos estudos de organização científica do trabalho na França. ${ }^{17}$

Segundo Bergman, mesmo que tenham sido necessários muitos anos para que a "teoria econômica" [que consistia no desenvolvimento dos conselhos de gestão, na normalização das regras e na ligação entre os preceitos fornecidos aos agricultores e os princípios da teoria da produção] se voltasse para o empirismo dos preceitos de bom senso, a partir dos anos 1960, uma demanda por estudos econômicos manifestava-se nos meios agrícolas. Particularmente viva em matéria de gestão, esta demanda começava a ser satisfeita. Graças aos esforços de alguns precursores, a posição da França no plano internacional "passava a melhorar pouco a pouco" (Bergman 1973:118). Dito de outro modo, foi este trabalho de instauração de novos esquemas de pensamento, mais amplamente acessíveis no mundo rural, que permitiu aos "camponeses" perceberem, por exemplo, seu gado, seu celeiro ou sua "terra" em termos de "capital de exploração" e tornarem-se "agricultores". ${ }^{18}$

A preocupação com o desenvolvimento de outros esquemas de pensamento, segundo Bergaman, seria indispensável em um país que desejasse permanecer democrático e que devesse fornecer "formação econômica contínua para diversas camadas da população" (Bergman 1973), e não se limitava à produção, já que

o futuro parece estar ligado a uma transformação completa da natureza das relações entre produtores, intermediários e consumidores, a uma integração mais estreita da agricultura na economia nacional [...] é preciso que os agricultores aceitem participar sem reticências da economia complexa e especializada que caracteriza a nossa época. Ela exige agricultores abertos ao mundo e à totalidade de seus problemas, agricultores que tenham recebido uma ampla formação geral e sejam esclarecidos por economistas que conheçam simultaneamente seus problemas e aqueles do conjunto da economia ${ }^{19}$ (Bergman 1960:8). 
Foram de fato os economistas que propuseram as categorias de cálculo para cada indivíduo, o que já implicava uma interdependência dos atores dos mercados. Tratou-se, realmente, de reverter uma posição de monopólio por parte dos compradores, tendo uma formação de preços mais eficaz e equitativa, e seria em torno da noção de mercado de concorrência imperfeita que os autores iriam trabalhar, sobretudo, R. P. De Farcy, professor titular na Ecole Nationale Supérieure de Angers. Artigos sobre a comercialização dos produtos agrícolas, esforços comerciais do agricultor, métodos de pesquisas no domínio do "marketing" nos Estados Unidos, margens de comercialização dos produtos alimentares (Farcy 1954, 1959a, 1959b, 1960) testemunhavam o interesse em transformar o agricultor tradicionalmente mais voltado para a produção, fosse em direção ao autoconsumo, fosse a uma produção destinada ao mercado.

Contudo, se esta abordagem da racionalização da ação parece constituir o objetivo procurado por um bom número de autores, seria falso pensar que esta última recobre a maioria dos trabalhos. Os artigos voltados para a produção, que representavam 22\% do número total de artigos entre 1949 e 1963, somente representam 13,44\% no período 1949-1988. Aqueles que se referem à problemática da comercialização, inexistentes nos primeiros anos, atingem 17,7\% nos anos 1960, para caírem novamente, em seguida, para cerca de 4\%, e apenas representam 13,4 \% entre 1949 e 1988 (Tanguy 1991:332-333). Se for preciso levar em conta o fato de que a associação não era a expressão de uma única corrente de pensamento e que ela pretendia ser, em certa medida, o lugar de debate por excelência no qual se exprimiam diferentes tendências, a própria natureza do empreendimento requeria um conhecimento adequado do meio ao qual esses modelos eram destinados e o recurso a outras disciplinas científicas para procurar facilitar a implantação dessas inovações, ou mesmo compreender e tentar remediar os eventuais problemas que elas pudessem suscitar. Os artigos dedicados à estrutura social da agricultura (a população agrícola, a sociedade rural, a mudança social, a agricultura familiar, os problemas fundiários, o crédito, a cooperação e a vulgarização) constituem 29,97\% dos artigos no período 1949-1988, a proporção crescendo ao longo dos anos seguintes (Tanguy 1991).

A necessidade de um conhecimento aprofundado da realidade social à qual se deveria impor um modelo capaz de contribuir para diminuir a distância dos demais países, como os Estados Unidos ou a Alemanha, explica o interesse pela rede "Economia e Humanismo" que, da perspectiva da ciência social subordinada à ação imediata, preocupada com a precariedade dos laços de solidariedade familiar e locais em decorrência do êxodo rural, situando-se nas antípodas da distância imposta pelas disciplinas universi- 
tárias, fixou sua atenção na família, no coração da exploração agrícola e na análise dos orçamentos. Foi de fato com um artigo de R. P. Allo, da seção "Pesquisas rurais de Economia e Humanismo", "Pesquisa sobre a mobilidade das famílias camponesas" (Allo 1949), que Augé-Laribé inaugurou a primeira seção da SFER, apresentando este último colaborador do Serviço de Estudos e de documentação do Ministério da Agricultura - organizador de pesquisas sobre situações agrícolas pouco conhecidas - enfatizando o fato de que pertencia ao grupo religioso e laico reunido em torno do padre Lebret. Vê-se bem a diversidade das tendências ideológicas que geraram um diálogo no contexto da SFER e da revista. É provável que a hegemonia posterior dos quadros de pensamento produzidos pela revista tenha sido reforçada por esta diversidade social, cultural e política dos diversos participantes e de suas redes. ${ }^{20}$

A importância das atividades de produção de estatísticas levadas a cabo por Vichy durante a Guerra para enfrentar uma economia de guerra perdurou diante da necessidade de subsequente reconstrução econômica. A criação do Comissariado, em 1946, e a criação do Instituto Nacional das Estatísticas e dos Estudos Econômicos, em 1945, favoreceram um trabalho de quantificação e de associação dos diversos fenômenos econômicos relativos às atividades econômicas na França (Pollak 1976). A agricultura não escapou desta preocupação, assim como o objetivo dos diferentes planos que iriam se suceder, pretendendo promover profundas modificações neste setor de atividades. Esta preocupação com a quantificação e a categorização dos rendimentos e das zonas de atividade manifestou-se na importância da produção de J. Klatzmann, diretor do INSEE no final dos anos 1940, diretor de Estudos na Ecole Pratique des Hautes Etudes, $6^{\text {a }}$ sessão (Klatzmann 1949, 1952, 1956a, 1956b).

A implantação desta agricultura moderna trouxe problemas que compreenderam, por um lado, a efetivação destas inovações e, por outro, os problemas sociais daí decorrentes ${ }^{21}$ a saber, uma forte diminuição da necessidade de mão de obra, uma reestruturação fundiária que ameaçava aqueles ligados a uma ordem social mais ou menos próxima da "ordem eterna dos campos".

Foi esta inscrição política da atividade dos economistas, que consistia em lutar contra a força dos notáveis e dos deputados eleitos pelo mundo rural, que se pretendia mais científica e defensora dos interesses da nação (a liga da livre troca reagrupava economistas renomados e industriais esclarecidos para denunciar o protecionismo como a razão maior do encarecimento da vida (Duby \& Wallon 1976:30), que os conduziu a inscreverem sistematicamente "ciências auxiliares", como diria Bergman, tais como a demografia 
e a sociologia, em seu programa de trabalho. A sociologia, inscrita desde o início no programa da $\mathrm{SFER}_{1}{ }^{22}$ está onipresente nos trabalhos de economistas rurais que deviam permitir, por um lado, conhecer a realidade sobre a qual se propunham a agir (Maget 1954; Sorre 1950) e, por outro lado, compreender por que os modelos que eles propunham encontravam obstáculos. O texto de L. Malassis é significativo a este respeito:

O economista rural observa e interpreta estruturas e comportamentos e propõe critérios e técnicas de decisão econômica. Cada vez mais, seu julgamento repousa sobre um cálculo. Mas o alcance de suas explicações e proposições depende do papel efetivo dos fatores econômicos no processo de evolução do setor agrícola. Ora, no seio da sociedade capitalista, a agricultura, que permanece artesanal, fez pouquíssimo cálculo econômico no passado e, atualmente, o número de explorações que realizam gestão é provavelmente inferior a $3 \%$. Os comportamentos, a modelagem das estruturas, os mecanismos de decisão dependem, portanto, mais ou menos, de fatores extraeconômicos, os quais devemos levar em conta para uma melhor interpretação do mundo rural [...] Como conclusão, a exploração agrícola familiar deve ser vislumbrada e interpretada em sua complexidade socioeconômica. Sociólogos, economistas, agrônomos e juristas podem trazer uma contribuição à elaboração de novas estruturas socioeconômicas de exploração agrícola, previstas pela lei de orientação, suscetíveis de atenuar os conflitos de geração e de facilitar a adaptação das estruturas da produção às necessidades do desenvolvimento econômico e social (Malassis 1961:5). ${ }^{23}$

\section{Um modelo que se esgota}

Após ter tido um desenvolvimento considerado satisfatório, particularmente com a publicação sobre "A economia agrícola francesa 1938-1958", e uma rápida progressão que permitiu aos efetivos e sócios aproximarem-se das 600 pessoas, em um artigo de balanço sobre as atividades da Revista, Bergman evoca as dificuldades que atravessavam a associação e a revista por conta da autonomização do campo da ciência econômica. Segundo ele,

as pessoas reunidas pela associação eram, a princípio, pessoas interessadas pela economia agrícola e não especialistas (com pouquíssimas exceções). Atualmente, há a diversificação crescente e o contato dificilmente se estabelece entre os especialistas, que atingem, algumas vezes, níveis muito elevados, e os conselheiros de base que se interessam pela economia, os homens honestos que 
procuram uma informação ampla e sobretudo palatável. O emprego do jargão, da matemática, não facilita as coisas... Caso se vise muito alto, a base e a massa não seguem. Se os objetivos são menos ambiciosos, os pesquisadores especializados se abstêm. Em segundo lugar, a concorrência é grande. No domínio das publicações, muitos suportes recobrem temas próximos aos nossos e se interessam pela economia rural. Várias reuniões, jornadas de estudos, congressos, conferências selecionam os temas da atualidade (Bergman 1964:13).

Observações que vão nesta mesma direção da análise de M. Pollak indicam uma diversificação das revistas em ciências sociais, tanto no polo científico quanto no polo de poder. Com estas transformações, a revista irá perder sua especificidade, seja a reunião em um local de trabalho de importação, de sintetização e de difusão dos quadros de pensamento para o cálculo do trabalho camponês e de seus resultados, seja a criação dos quadros mentais necessários para a articulação ou a produção das interdependências necessárias às redes de mercado em escala nacional e internacional. O conhecimento da economia desse período supõe o conhecimento do trabalho de produção das categorias de pensamento e dos esforços dos economistas para difundi-los ou, simplesmente, a "pedagogia do mercado agrícola".

A análise da produção da revista Economie Rurale e as produções correlatas postas em relação com as propriedades sociais de seus criadores e autores, bem como os quadros institucionais que caracterizam a França do pós-guerra, demonstram a importância das "representações científicas" como elemento essencial das transformações subsequentes na economia rural. A proximidade dos economistas do poder, a preocupação permanente com uma reflexão voltada para a ação em um período de reconstrução, no qual a planificação econômica ganha uma dimensão bastante importante, são elementos-chave para a compreensão da força que adquirem os modelos divulgados pela revista. A análise do movimento da juventude agrícola católica, do sindicalismo e dos grupos de vulgarização mostra-se, no entanto, indispensável para se compreender como as representações puderam encontrar um eco favorável entre estas diversas organizações e agentes de difusão de conhecimentos científicos, contribuindo, deste modo, para a instauração de uma nova racionalidade econômica no mundo rural.

Se nesta configuração particular os modelos pensados por economistas, ao ocuparem um lugar específico nos campos científicos e de poder, tornaram-se em grande parte realidade, não se deve esquecer que o próprio campo da economia é atravessado por concepções diversas e, de todo modo, que as diferentes "forças sociais" podem, segundo o contexto, apoiar-se ou não sobre uma ou outra formulação. A análise específica exposta acima não 
poderia de modo algum dar conta do que chamamos de a "performatividade" da economia. Cada configuração deve ser estudada em sua especificidade. Como exemplo, cito o caso da regulação do mercado dos serviços jurídicos mencionado em L'économie des singularités, por Lucien Karpik (2007): se a teoria neoclássica mostra-se inspiradora da Comissão europeia para julgar a atual regulação, apoiando-se mais na confiança do que nos preços como fonte de rendas a entravar seu bom funcionamento, é um contexto inteiramente distinto o que se oferece ao olhar do analista: os economistas neoclássicos que estão na origem desta visão estariam tão próximos do poder quanto estavam os economistas rurais na França do pós-guerra? A ordem dos advogados não gozaria de certa força para resistir à pressão da Comissão europeia? São tantos elementos em meio a outros tantos que nos levam a pensar que uma análise específica mostra-se indispensável para que se reflita sobre o papel das representações científicas.

Recebido em 07 de junho de 2009

Aprovado em 09 de fevereiro de 2010

Tradução de Roberta Ceva

Marie-France Garcia-Parpet é pesquisadora do Institut National de la Recherche Scientifique (INRA) e pesquisadora vinculada ao Centre de Sociologie Européenne. E-mail: <garcia@ivry.inra.fr>

\section{Notas}

${ }^{1}$ Foi a leitura do artigo de Pierre Bourdieu, "Espace social et genèses des 'classes'", que chamou a nossa atenção para esta questão. Neste trabalho, o autor demonstra o efeito produzido pelo conceito de classes sociais - formulado por Karl Marx - na formação destas últimas (Bourdieu 1984).

2 Para a produção sociológica que abordou estas transformações, ver, entre outros: Bourdieu 2002; Champagne 2002; Lagrave 1987; Maresca 1983 e Mendras 1967, 1976.

${ }^{3}$ Criado em 1929 para salvar os "valores cristãos e camponeses", o movimento da Juventude Agrícola Católica afastou-se de uma visão estritamente religiosa do mundo no período do pós-guerra e apostou no progresso técnico e na organização 
dos produtores para assegurar a promoção social dos pequenos produtores. Os jovens agricultores propalavam uma política fundiária que favorecesse a promoção de uma elite agrícola desejosa de integrar-se ao capitalismo, mas preservando sua independência econômica e social. Impregnados de uma ideologia modernista e produtivista, eles integraram a organização sindical existente (a Federação Nacional dos Sindicatos Agrícolas) e criaram o Centro Nacional dos Jovens Agricultores que, formalmente sob tutela da Federação, iria desenvolver um programa que permitiria aplicar na agricultura os princípios industriais de produção, dissociando a família da exploração e o capital da exploração do capital fundiário (Duby \& Wallon 1976).

${ }^{4}$ As leis de orientação agrícola de 1960 e 1962 constituem um elemento essencial da política da $5^{\text {a }}$ República, que procura acelerar a integração da agricultura ao sistema capitalista francês, no momento em que este último se abre plenamente ao exterior. Elas consistem em uma lei-programa de equipamento, uma lei fundiária, uma lei sobre o ensino agrícola e uma lei que cria o seguro de saúde para os trabalhadores agrícolas.

${ }^{5}$ É preciso notar que a SFER foi criada dois anos antes da Société Française de Science Economique, que surgiu somente em 1950, bem depois da American Economic Association, em 1885, e da British Economic Association, em 1846 (Lebaron 2000).

${ }^{6}$ Lebaron (2000) analisa as estratégias existentes a propósito da definição desta profissão.

${ }^{7}$ Esta composição da direção do SFER, que é também a da Revista, é bem diferente da Etudes Rurales, revista trimestral de história, geografia, sociologia e economia rural, criada em 1961 e cujos direção e comitê de redação comportavam um grande número de membros que pertenciam ao topo da hierarquia universitária: seus diretores eram G. Duby, professor na universidade de Aix Marseille, e D. Faucher, catedrático, honorário da faculdade de Letras de Toulouse e correspondente do Instituto.

${ }^{8}$ Entre os quais, uma proporção relativamente importante de professores, funcionários, representantes de organizações profissionais, agrônomos, juristas e uma proporção importante de eclesiásticos que ensinavam ou trabalhavam em consultorias privadas.

${ }^{9}$ Grifos nossos.

${ }^{10}$ Louis Malassis publicou 21 artigos na revista Economie Rurale, ficando atrás somente de Denis Bergamn (31), Jean-Marc Boussard (27) e J. Klatzmann (25).

${ }^{11}$ Grifos nossos.

${ }^{12}$ Frédéric Lebaron mostra que a gestão é simultaneamente ensinada nas escolas de gestão e como disciplina de formação em uma instituição que se destina à ciência econômica (Lebaron 2000). 
${ }^{13}$ Particularmente Jean Stoetzel, diretor do CES, aluno de Paul Lazarfeld (Pollak 1976).

${ }^{14}$ Cf. a análise por repartição geográfica em Tanguy (1991:337-338) e os artigos que fazem referência aos Estados Unidos (Serve 1950; Le Gouis 1961; Dubourgnoux 1964; Koeller 1953).

${ }^{15}$ A este respeito, Denis Bergman enfatiza a obtenção por J. M. Boussard do prêmio de melhor artigo publicado no American Journal of Agricultural Economics (por um artigo sobre a programação).

${ }^{16}$ Político de centro-esquerda.

${ }^{17}$ Particularmente aquele de Piel-Desruisseaux (1958), diretor do Instituto de Organização Científica do Trabalho em Agricultura, uma instituição que se propunha a aplicar a organização científica do trabalho industrial à agricultura, e o artigo de "Avaliação das necessidades de trabalho em uma exploração agrícola", de Claude Reboul, inicialmente membro do Instituto de Organização Científica em Agricultura, em seguida, pesquisador no INRA, que se propôs neste artigo a "mostrar as insuficiências dos métodos utilizados na França para analisar e prever o emprego dos meios de trabalho sobre uma exploração agrícola e mostrar, tendo como base a experiência adquirida pelo CNCER, como sua insuficiência conduziu-a ao estudo dos trabalhos estrangeiros, particularmente os do Dr. Kreher, no Instituto Max Planck de BadKreuznach" (Reboul 1960:55). Por ocasião de uma apresentação deste trabalho no contexto de um seminário do Museu Nacional, pesquisadores chamaram a atenção para o fato de que as preocupações dos economistas se voltavam para a produção agrícola francesa, deixando de lado os territórios coloniais. A problemática do "desenvolvimento", da qual François Perroux era um dos principais autores, constituiu-se em um contexto institucional inteiramente distinto.

${ }^{18}$ Isto supõe uma aceitação por parte dos camponeses, a qual deveria ser objeto de uma análise em separado. Os trabalhos realizados por Jérôme Pelletier sobre os grupos de vulgarização agrícola parecem confirmar esta adesão (Pelletier 2007).

${ }^{19}$ Grifos nossos.

${ }^{20}$ Isto nos permite compreender as qualidades "sociológicas" de AugéLaribé evocadas em uma nota necrológica anônima, testemunhando o fato de que ele "conhecia a fundo o assunto". Ele insistia, notemos, em que os economistas "especializando-se na economia rural, substituam a atividade econômica agrícola no contexto da sociedade e que mantenham contatos estreitos com representantes das outras disciplinas, particularmente com sociólogos", a sociologia sendo entendida aqui como elemento associativo, facilitando a recomposição dos laços entre grupos sociais atravessados por todo tipo de oposições nesta nova inscrição do campesinato no sistema de mercado formador de preço (Augé-Laribé anônimo 1954). 
${ }^{21}$ Sobre este ponto, cf. Ratineau: "Não se deve esquecer o problema humano; o explorador deve se esforçar para assegurar trabalho a seus operários durante o ano todo. A mecanização total torna o problema de difícil solução" (1949:89).

22 "A associação tem por objetivo promover estudos de economia rural de caráter científico, voltados para os problemas econômicos e sociológicos da França" (Bulletin de la Société Française d'Economie Rurale 1949).

${ }^{23}$ Artigo que figura em um número dedicado aos problemas sociológicos, entre outros, com um artigo de Mendras (1961). Para compreender qual é o objeto da sociologia para os economistas rurais, particularmente no seio do INRA, ver a comunicação de Alice Bartez (2006).

\section{Referências bibliográficas}

ALLO, Révérend Père. 1949. "Enquête sur la mobilité des familles paysannes". E. R., 2:2-6.

ANONYME.1954. "M. Augé-Laribé (1976-1954)". E. R., 21:3-4.

AUGÉ-LARIBÉ, Michel. 1907. Le problème agraire du socialisme. La viticulture industrielle du Midi de la France. Paris: V. Girard \& Brière. 363p.

- 1912. L'évolution de la France agricole. Paris: A. Colin. 304p. 1923. Le paysan français après la guerre. Paris: Garnier Frères. 202p. -1926. Syndicats et coopératives agricoles. Paris: A. Colin. 211p.

1941. Situation de l'agriculture française 1930-1939. Paris: Berger-Levrault. . 1949a. "Essai de définition des termes usuels de l'économie rurale". E. R., 2:31-39.

1949b. "Essai de définition des termes usuels de l'économie rurale". E. $R ., 3: 67-73$.

. 1950a. "Essai de définition des termes usuels de l'économie rurale". $E$. R., 4:15-17. 1950b. "Essai de définition des termes usuels de l'économie rurale". E. $R$, 6:71-75.

AUGÉ-LARIBÉ, Michel \& CHOMBART DE LAUWE. 1953. "L'orientation des travaux de la société". E. R., 17:38.

BARTEZ Alice. 2006. "Au sujet de l'historicité du regard scientifique. Les mondes ruraux à l'épreuve des sciences sociales". In: C. Bessière et alii (orgs.), Actes du colloque: les mondes ruraux à l'éprevue des sciences sociales. Dijon, 17 a 19 de maio de 2008, INRA, MSH, CNRS. pp. 427-441

BELHOMME, Henry. 1964. "Où en est la constitution des groupements de producteurs et des comités économiques agricoles?". E. R., 60:44-52.

BERGMAN, Denis. 1960. "Tour d'horizon sur les problèmes de commercialisation agricoles". E. R, 44:8. 1964a. "Essai d'analyse du contenu de la revue économie rurale depuis sa fondation". E. R., número especial, p.118. 
. 1964b. "Les recherches en économie rurales, essai de bilan et perspectives". E. R., 96:133.

. 1973. "Les recherches en économie rurale à l'INRA. Essai de bilan et de perspectives". E. R., 96:118.

Bulletin de la Société Française d'Economie Rurale. 1949. 1(1).

Bulletin de la SFER. 1951. III(1).

BUSTARET, J. 1951. “La rentabilité agronomique". E. R., 8:82-84.

BOURDIEU, Pierre. 1984. "Espace social et genèses des classes". Actes de la Recherche en Sciences Sociales, 5253:3-14.

. 2002. Le bal des célibataires. Paris: Seuil.

CHALMIN, P., PISANI, Edgard \& DEBATISSE, Michel. 1988. "Les leçons du passé face aux interrogations du futur". E. R., 187:59-65.

CHAMPAGNE, Patrick. 2002. L'héritage refusé. Paris: Seuil.

CÉPÈDE, Michel \& CHOMBART DE LAUWE. 1969. "Michel Augé-Laribé, Président fondateur de la SFER". E. R., 79:9-11.

CHOMBART DE LAUWE. 1957. Gestion des exploitations agricoles. Paris: Dunod.

DEBATISSE, Michel. 1974. "Questions syndicalistes au sociologie rural". E. R., 103:2-21.

DEBROUX, J. 2004. "Une association pour 'organiser les études rurales', l'Association des Ruralistes Français". L'Homme et la Société, 154:199-219.

DENIS, Henry. 1964. "L'idée coopérative devant l'évolution économique du temps présent". E. R., 62:11-16.

DOUROUX , L. 1964. "La position des agriculteurs en face de d'économie contractuelle". E. R., 60:75-77.

DUBOURGNOUX, J. C. 1964. "Aspects de la situation actuelle de l'agriculture contractuelle aux Etats-Unis". E. R., 60:9-23.
DUBY, Georges \& WALLON, A. 1976. Historie de la France rurale, t. 4. Paris: Seuil.

DUPUIS, J. 1964. "Quelques aspects généraux de l'économie contractuelle dans une perspective d'expansion". E. R., 60:85-89.

Economie Rurale. 1957. Les investissements en agriculture, $\mathrm{n}^{\circ} 31$.

Economie Rurale. 1964a. Groupements et contrats de commercialisation, $\mathrm{n}^{\circ} 60$.

Economie Rurale. 1964b. La coopération agricole, $\mathrm{n}^{\circ} 62$.

FABREGUES, J. H. De. 1964. "L'état actuel des groupements de producteurs". $E$. $R$., 60:79-83.

FARCY, de, Révérend Père. 1954. L'agriculteur est-il prêt à vendre ses produits?". E. R., 20:3-7. . 1958. "L'effort commercial des agriculteurs aux Etats-Unis. La promotion des ventes". E. R., 35:23-32. . 1959a. "La commercialisation des produits agricoles". E. R., 39:103105.

. 1959b. "L'amélioration du fonctionnement des marchés agricoles". $E$. R., 41:43-45. . 1960. "Méthodes de recherche dans le domaine du 'marketing' agricole aux Etats-Unis". E. R., 44:27-32.

GARCIA-PARPET, Marie-France. 1996. "Répresentations savantes et pratiques marchandes". Genèses, 25:50-71.

GÉNIN, M. Michel. 1964. "La position des industriels en face de l'économie contractuelle". E. R., 60:69-73.

KARPIK, Lucien. 2007. L'économie des singularités. Paris: Gallimard.

KLATZMANN, J. Joseph. 1949. "La distribution des revenus agricoles; les revenus bruts par exploitation". Etudes et Conjonctures, 5. . 1952. "La classification des entreprises agricoles suivant leur importance économique". E. R., 12:38-58. 
. 1956a. "La localisation des productions agricoles". E. R., 28:3-15.

. 1956b. "Délimitation et importance des régions agricoles insuffisamment développées". E. R., 29:3-15.

KOELLER, H. L. 1953. "Les méthodes utilisées pour calculer le prix de parité des produits agricoles aux Etats-Unis". E. R., 17:3-9.

LAGRAVE, Rose-Marie (org.). 1987. Celle de la terre, l'invention politique d'un métier. Paris: EHESS.

LEBARON, Frédéric. 2000. La croyance économique, les économistes entre science et politique. Paris: Seuil.

LE BIHAN, Joseph. 1964. "La croissance de la coopération en Bretagne". E. $R ., 62: 35-41$.

LE GOUIS, Michel. 1961. "La commercialisation des fruits et légumes aux Etts-Unis". E. R., 49:39-50. . 1964. "L'effet de réseau dans la commercialisation des produits agricoles périssables". E. R., 60:25-44.

LOPES-CARDOSO, A. 1964. "Doctrine coopérative et coopération agricole". E. R., 62:23-29.

LEBARON, Frédéric. 2000. La croyance économique, les économistes entre science et politique. Paris: Seuil.

MACKENZIE, Donald; MUNIESA, Fabien \& SIU, Lucia (orgs.). 2007. Do economists make markets? On the performativity of economics. Princeton: Princeton University Press.

MAGET, Marcel. 1954. "Les recherches d'ethnographie en milieu rural". E. R., 21:19-22.

MALASSIS, Louis. 1957. "Les investissements dans l'agriculture: Conclusions". E. R., 31:43-46.

. 1961. "Préoccupations sociologiques d'un économiste rural". E. $R$., 47:3-10.

1964. "Essai d'orientation sur l'évolution de la coopération en France". E. R., 62:25-33
MAINIÉ, Philippe. 1957. "Bibliographie". E. R., 32:41-42 . 1964. "Conclusions de la session de la SFER de mai 1964: une extension des relations contractuelles est-elle possible?". E. R., 60:91-96.

MANSHOLT, Sicco. 1973. "Comment les économistes agricoles peuvent-ils contribuer à la solution des problèmes agricoles en Europe?". E. R., 97:3-7.

MARESCA, Sylvain. 1983. Les dirigeants paysans. Paris: Minuit.

MASPETIOL, Roland. 1946. L'ordre éternel des champs. Paris: Librairie Médicis. 587p.

MENDRAS, Henri. 1961. "Objet, méthodes et organisation de la sociologie rurale". E. R., 47:67-72. . 1967. La fins des paysans. Paris: SEDEIS. 1976. Société paysanne, éléments pour une théorie de la paysannerie. Paris: Armand Collin.

MOISAN, V. 1964. "La formation des agriculteurs, des administrateurs et des cadres de la coopération agricole". E. R., 62:71-77.

MOREAU, Raymond. 1955. "Le capital foncier et la rentabilité des entreprises". E. R., 24:9-17. . 1959. "Le capital d'exploitation". E. $R ., 39: 29-36$

MOREAUX, J. 1964. "L'analyse critique de la loi sur l'économie contractuelle". E. R., 60:53-67.

NEIBURG, Federico. 2006. "1975/1978. Inflation: economists and economic cultures in Brazil and Argentina". Comparative Study for Society and History, 48(3):604.

PELLETIER, D. 1996. Economie et humanisme. De l'utopie communautaire au combat pour le tiers-monde 19411966. Paris: Cerf.

PELLETIER, Jérôme. 2007. "La vulgarisation féminine agricole: CETMA et GVAF en Loir-et-Cher de la fin 
des années 1950 au milieu des années 1960". Journée Sciences, agriculture, alimentation, INRA, 25 octobre 2007.

PIEL-DESRUISSEAUX, J. 1958. “Etat actuel et perspectives des études d'organisation scientifique du travail en France". E. R., 35:19-22.

PIETTRE, André. 1964. "La place de l'économie contractuelle dans l'économie française". E. R., 60:3-8. POITEVIN, J. 1959. "Les progrès en matière de gestion et d'organisation des entreprises agricoles". E.R., 39:49-61.

POLLAK, Michel. 1976. "La planification des sciences sociales". Actes de la Recherche en Sciences Sociales, 23:105-121.

RATINEAU, J. 1949. "La rationalisation de l'exploitation agricole". E. R., 3:89-90.

REBOUL, Claude. 1960. "L'évaluation des besoins en travail dans une exploitation agricole". E. R., 43:55.

REMERY, R. 1953. "Remarques sur les concepts et la mesure de la productivité". E. R., 38:25-28.

SELARIES, G. 1964. "Les interventions de la coopérative sur les décisions de la production". E. R., 62:53-59.

SAUVAGE, A. 1964. "L'application des méthodes de gestion aux organisations coopératives". E. R., 62:43-51. SERVE, Révérent Père. 1950. "La mécanisation de la ferme familile aux Etats-Unis - Conclusions qu'on peut en tirer pour la France". E. R., 3:86-87.

SORRE, E. 1950. "Economistes ruraux et géographes". E. R., 4:2-3.

TANGUY, Nicole. 1991. Répertoire bibliographique rétrospectif de la revue Economie Rurale 1949-1988. Ivry/Seine: INRA. 349p.

TAVERNIER, Yves. 1964. "L'actualité politique - Les aspects permanents de la crise paysanne en 1964". E. R., 62:5-10.

TUGAUlT, J. 1949. "Les méthodes de calcul des prix de revient agricoles". E. R., 2:40-64.

VOISIN, A. 1953. "Production du fumier et productivité agricole". E. R., 18:29-32. 
Resumo

Este artigo propõe-se a analisar o papel das instituições de pesquisa e científicas que contribuíram, juntamente com os sindicatos e as organizações profissionais agrícolas, para modelar a identidade social do campesinato e fazer com que as explorações agrícolas fossem pensadas e geradas como uma empresa como qualquer outra. Nós nos debruçaremos, particularmente, sobre a criação e a produção da Revista Economie Rurale, seus enunciados e a identidade social de seus autores, confrontando-os com a produção intelectual difundida por outras revistas para estudar o modo como os modelos econômicos importados do universo intelectual norte-americano contribuíram para o reconhecimento de uma racionalidade econômica tida como a única via da evolução histórica.

Palavras-chave Economia performativa, Agricultura, Categorias de percepção

\section{Abstract}

The following study assesses the contribution of research bodies, individual scientists, farming unions and agricultural trade organisations to shaping the social identity of the peasant classes and gradually causing agriculture to be conceived and managed like any other business enterprise. Special attention is given to the launch and published issues of Economie rurale, including the ideas championed in the journal and the social profile of its contributors. These are compared and contrasted with the ideas and authors promoted in other journals in order to study the way in which economic models imported from the United States led to economic rationality becoming recognized as the only path to historical evolution.

Key words Performative economics, Agriculture, Categories of perception 